\title{
Effects of a self-management education program on self-efficacy in patients with COPD: a mixed- methods sequential explanatory designed study
}

This article was published in the following Dove Press journal:

International Journal of COPD

20 July 2017

Number of times this article has been viewed

\section{Wai I $\mathrm{Ng}^{\prime}$}

Graeme Drummond Smith²

'Education Department, Kiang Wu Nursing College of Macau, Macau SAR, People's Republic of China; ${ }^{2}$ Education Department, School of Health \&

Social Care, Edinburgh Napier

University, Edinburgh, Midlothian, UK

Correspondence: Wai I Ng

Kiang Wu Nursing College of Macau, Est Repouso Number 35, R/C, Macau SAR,

People's Republic of China

Tel +8685382956218

Fax +8685328365204

Email nwi@kwnc.edu.mo
Background: Self-management education programs (SMEPs) are potentially effective in the symptomatic management of COPD. Little is presently known about the effectiveness of these programs in Chinese COPD patients. The objective of this study was to evaluate the effectiveness of a specifically designed SMEP on levels of self-efficacy in Chinese patients with COPD.

Materials and methods: Based on the Medical Research Council framework for evaluating complex interventions, an exploratory phase randomized controlled trial was employed to examine the effects of an SMEP. Self-efficacy was the primary outcome using the COPD Selfefficacy Scale, measured at baseline and 6 months after the program. Qualitative data were sequentially collected from these patients via three focus groups to supplement the quantitative findings.

Results: The experimental group displayed significant improvement in their general self-efficacy $(Z=-2.44, P=0.015)$ and specifically in confronting 1$)$ physical exertion $(Z=-2.57, P=0.01)$, 2) weather/environment effects $(Z=-2.63, P<0.001)$ and 3$)$ intense emotions $(Z=-2.54, P=0.01)$. Three themes emerged from the focus groups: greater disease control, improved psychosocial well-being and perceived incapability and individuality. The connection of the quantitative and qualitative data demonstrated that individual perceptual constancy of patients could be a determining factor modulating the effectiveness of this type of intervention.

Conclusion: These findings highlight the potential putative benefits of an SMEP in Chinese patients with COPD. Further attention should be given to cultural considerations when developing this type of intervention in Chinese populations with COPD and other chronic diseases.

Keywords: COPD, embedded design, exploratory randomized controlled trial, mixed methods, self-efficacy, self-management

\section{Introduction}

Globally, COPD places a serious burden on society, in terms of disability-adjusted life years (DALYs). ${ }^{1}$ With increased tobacco use and global aging population, a significant increase in COPD morbidity is forecasted in the future. ${ }^{2,3}$ Symptoms of COPD include chronic cough, sputum production and exertional dyspnea, and there is worldwide consensus that COPD symptoms are potentially manageable., ${ }^{4,5}$ Self-management education programs (SMEPs) have been shown to improve COPD intervention, particularly in symptom relief, by empowering patients with daily living management skills. ${ }^{67}$ In Macau, a special administrative region of China, obstructive airway disease was one of the top-ten causes of death from 2004 to $2011 .{ }^{8,9}$ Historically, gambling casinos were the frontline of cigarette smoke exposure for the local population. A total of $14 \%$ of the manpower in the city were serving in the gambling industry where 
smoking was permitted before October 2014. ${ }^{10}$ Inhalation of second-hand cigarette smoke was ranked as the highest occupational hazard in their working environment; ${ }^{11}$ this potentially poses a greater risk of increased COPD morbidity in Macau in the coming decades.

Recently, the implementation of self-management interventions in chronic illness has received a great deal of attention from health care professionals in certain regions of Mainland China. ${ }^{12-15}$ This form of continuous health care service may be especially suitable for chronic disease patients from the Chinese ethnic group. These patients generally demonstrate inadequate health knowledge and behavior regardless of education level. ${ }^{16,17}$ Chinese patients have expressed a preference to applying informal advice acquired from media and friends to promote their own health. ${ }^{18,19}$ Follow-up care, in particular, SMEP, has extensively been used in Western countries for incorporating cognitive elements to challenge irrational medical beliefs. ${ }^{20,21}$ It can positively influence selfefficacy that mediates health-related behavioral changes of patients. ${ }^{12-15}$ Higher self-efficacy is found to be associated with the reduction of anxiety and depression in patients living with COPD. ${ }^{22}$ Multicomponent of self-management interventions can also improve health-related quality of life and lead to considerable cost-effectiveness. ${ }^{23-25}$ Thus far, studies concerning self-management or nursing care for COPD patients in Macau are scarce, ${ }^{26,27}$ and $>90 \%$ of the residents in Macau are of Chinese origin. ${ }^{28}$ Therefore, it is important to explore the effectiveness of SMEP and impact on self-efficacy in these COPD patients.

Instead of importing a Western style of self-management care directly into clinical practice in Macau, it is necessary to examine the appropriateness and feasibility of this approach in local COPD patients. Accordingly, the primary objective of this study was to compare the self-efficacy of Chinese COPD patients before and after the delivery of a newly initiated self-management intervention tailored for COPD patients in Macau. A secondary aim was to explain the primary results with a qualitative approach so as to understand the effects of a self-management intervention on these patients in a comprehensive way. Data collected from this study will also have potential implications for the use of self-management strategies in other forms of chronic illness in Chinese patients.

\section{Materials and methods Design}

Under the Medical Research Council (MRC) framework for the evaluation of complex interventions, this study used an exploratory randomized controlled trial (RCT). ${ }^{29}$ It followed an embedded design where a mixed-methods sequential explanatory approach was adopted. ${ }^{30}$ Exploratory trial is the second phase of evaluation of RCT for complex interventions, and it is appropriate to use this design in a study that is conducted in a place where there is lack of relevant theoretical and empirical basis, such as in Macau. ${ }^{29}$ Before progressing to a definitive RCT, the MRC framework advocates undertaking a separate exploratory study of a complex intervention to address all the components and outcome measures, rather than being as part of the overall evaluation package. This approach has previously been advocated in nursing academic research. ${ }^{31}$ In the sequential explanatory approach, the primary focus was on quantitative data (COPD Self-efficacy Scale [CSES]), which was collected in the first (pre-test) and second (6 months after intervention) phases, and qualitative data (focus groups) were collected in the third phase (follow-up of second phase) (as shown in Figure 1). By using this approach, predetermined important topics identified in the quantitative phase of the study were sequentially included in the qualitative data collection, and this could help to explain the participants' response and enhance the overall experimental design. ${ }^{30}$ The study was conducted at the outpatient department of a hospital and community centers of Macao. The ethical approval was obtained from the research ethics committees of the University of Edinburgh (Level 2 approval-20/01/2011), Kiang Wu Nursing College of Macau (approval letter reference number 2011MAR07) and Kiang Wu Hospital (approval letter reference number (11)001), where data were collected.

\section{Participants}

Patients were recruited consecutively from one of the two largest hospitals in Macau and three community care centers for older people for 20 months (January 2011 to August 2012). They fulfilled the Global Initiative for Chronic Obstructive Lung Disease (GOLD) (2008) diagnostic criteria of COPD post-bronchodilator stages II-IV and were aged 40 years or above in a stable condition. ${ }^{32}$ Patients with reversible asthma, congestive heart failure, lung carcinoma, bronchiectasis, pulmonary tuberculosis, bronchiolitis obliterans and interstitial lung diseases were excluded. All patients were approved to participate in this study and consented in writing to perform pulmonary function test for confirming diagnosis by their attending doctors. Written informed consent was collected from all participants by the principal researcher who did not involve in their clinical care. Then, they were allocated by block randomization to either experimental group 


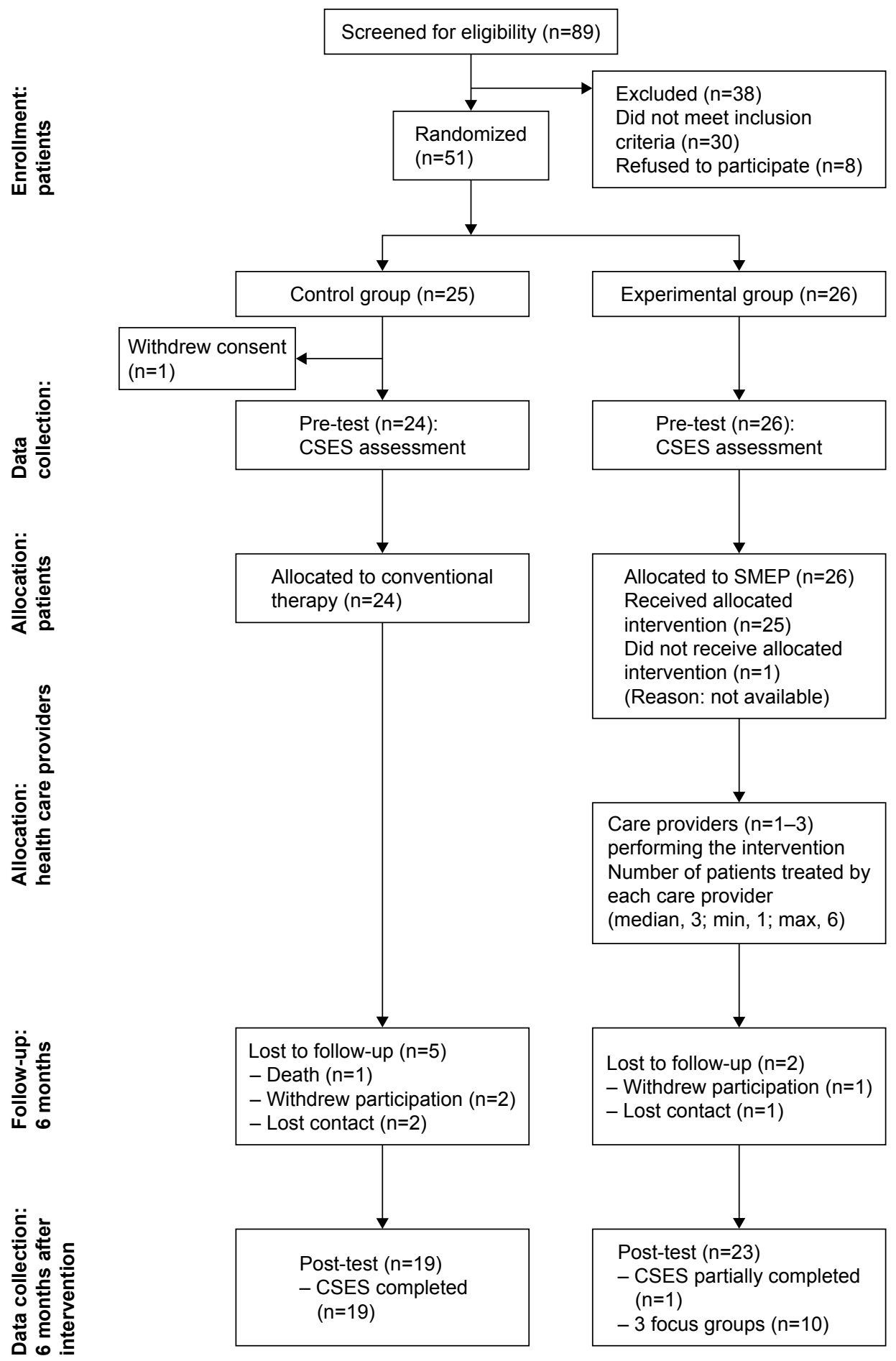

Figure I Trial flow.

Abbreviations: CSES, COPD Self-efficacy Scale; SMEP, self-management education program; min, minimum; max, maximum.

(assigned SMEP on top of conventional therapy) or control group (conventional therapy) by drawing cards at random by the participants. The blocking was conducted in terms of the stages of disease severity, with consented participants of the same stage of severity being randomly assigned to either experimental or control group. Conventional therapy involved routine visits to the physicians and use of the prescribed medicine. In the qualitative strand of this embedded design, purposive sampling was adopted for the focus group to reflect diversity and provide the maximum possibilities for comparison. ${ }^{33}$ Participants of the focus groups were purposively selected from the experimental group using 
matched characteristics, such as age, gender, stage of disease severity and family conditions, as these have been shown to be associated with the effects of any education programs on patients in previous COPD studies. ${ }^{34-36}$

\section{Intervention}

The establishment of the SMEP in this study followed MRC guidelines for developing a complex intervention, consisting of three components: 1) self-management education workshops, 2) a patient handbook and 3) a monthly telephone follow-up. The specifically designed self-management education workshops comprised of an overview of the definition of COPD, natural course of disease, information on how to manage a stable condition, advice on how to prevent complications and a self-treatment guideline (or action plan) for managing exacerbations. ${ }^{37}$ Content validity was performed on the protocol of the workshops, and it demonstrated high validity both in appropriateness (content validity index [CVI] $=0.95)$ and in feasibility $(\mathrm{CVI}=0.93)$. The self-management education workshops were conducted on group basis with five to eight participants in each section. They were delivered to the experimental group by the principal researcher over three 1.5-hour nurse-led sections that ran over 3 consecutive weeks at a demonstration room in the clinical setting.

\section{Instrument and data collection}

Demographic data including age, sex, disease severity by GOLD classification and educational status were collected at baseline. CSES was developed from Bandura's Self-Efficacy theoretical framework and has been commonly used in COPD studies that examine self-efficacy. ${ }^{22,38}$ CSES was specifically chosen to measure self-efficacy of patients in the quantitative strand of the study. The CSES consists of 34 items exploring five dimensions of self-efficacy: 1) negative effect, 2) intense emotional arousal, 3) physical exertion, 4) weather/ environment and 5) behavioral risk factors. The five factors show a good validity and internal consistency (Cronbach's alpha $=0.95) .{ }^{39}$ CSES has been translated into simplified Chinese and validated for an interventional study. ${ }^{38}$ With the permission granted by Wong, the scale was converted into traditional Chinese version that is the native written language in Macau. Three experts in nursing, education or clinical respiratory nursing who comprehend both forms of Chinese were invited to validate the items of the scale with respect to language expression. The CVI was computed and scored 0.91 (ranged from 0.67 to 1.00 ). The questionnaires were completed through face-to-face interviews during clinical consultation with the patient. In the qualitative strand, focus groups were used to explore the self-efficacy perception of COPD patients after application of self-management skills. The interview guide included three focus open-ended questions, such as "how do you manage breathing difficulty?" Both quantitative and qualitative data were collected by trained investigators and an experienced moderator who were independent from this study in the clinical setting.

\section{Data analysis}

SPSS 13.0 software was used to analyze the quantitative data, producing percentage, mean and standard deviation (SD) for descriptive data, and Mann-Whitney $U$-test and Wilcoxon signed-rank tests were computed for inferential statistics. Statistical significance was set at the level of $P<0.05$. In the qualitative strand, the focus groups were audio-taped and transcribed, and thematic analysis was performed. Connected mixed-methods data analysis was adopted to interpret sequential results. Following Creswell and Plano Clark's ${ }^{30}$ proposition, a larger interpretation was drawn in the "Discussion" section to connect the mixed-methods findings for addressing the mixed-methods questions and providing a more generalized understanding and perspective of the phenomenon.

\section{Results Quantitative phase Sociodemographics}

In accordance with CONSORT guidance, a trial flow diagram was produced (Figure 1). A total of 89 COPD patients were selected, and 50 of them fulfilled the inclusive criteria and consented to the study. They were randomly allocated to experimental group $(n=26)$ and control group $(n=24)$. The dropout rate was $17.6 \%$ throughout the trial. In terms of demographic data (Table 1), the mean age of the participants was 67.9 years (SD 10.2 years), and $74 \%(n=37)$ were male. A total of $52 \%$ $(n=26)$ received primary level of education, and amount of smoking made up a mean of 13.2 pack years (SD 25.7); 58\% ( $n=29)$ of the participants belonged to stage III or above. The average year of being diagnosed of COPD was 8.4 (SD 8.6) (range 1.0-30.0). Their post-bronchodilator forced expiratory volume in $1 \mathrm{sec}-$ ond $\left(\mathrm{FEV}_{1}\right) \%$ predicted was on average $47.9 \%$ (SD 16.5) (range 15.0-79.0). A total of $72 \%$ (36 participants) had at least one concomitant disease. Regarding the medical expenses, most participants adopted a mix of public medical coverage $(72 \%$, 36 participants) and self-payment (72\%,36 participants). Table 2 demonstrates no statistical difference in variables between the experimental and control groups at baseline. 
Table I Demographic characteristics of the study population

\begin{tabular}{|c|c|c|c|c|}
\hline & $\begin{array}{l}\text { Mean } \\
(n=50)\end{array}$ & SD & Frequency & $\%$ \\
\hline \multicolumn{5}{|l|}{ Demographic characteristics } \\
\hline \multicolumn{5}{|l|}{ Sex } \\
\hline Male & & & 37 & 74 \\
\hline Female & & & 13 & 26 \\
\hline Age & 67.9 & 10.2 & & \\
\hline \multicolumn{5}{|l|}{ Education level $(n=42)$} \\
\hline Illiterate (uneducated) & & & 7 & 14.0 \\
\hline Primary level & & & 26 & 52.0 \\
\hline Secondary level & & & 15 & 30.0 \\
\hline Tertiary level or above & & & 2 & 4.0 \\
\hline \multicolumn{5}{|l|}{ Smoking habit } \\
\hline Nonsmoker & & & 16 & 32.0 \\
\hline Current smoker & & & 12 & 24.0 \\
\hline Ex-smoker & & & 22 & 44.0 \\
\hline $\begin{array}{l}\text { Amount of smoking in pack } \\
\text { years }(S D)\end{array}$ & 13.2 & 25.7 & & \\
\hline \multicolumn{5}{|l|}{ Working status } \\
\hline Retired or Never work & & & 24 & 48.0 \\
\hline Currently working & & & II & 22.0 \\
\hline Unemployed & & & 5 & 10.0 \\
\hline $\begin{array}{l}\text { Lost working ability due } \\
\text { to disease }\end{array}$ & & & 10 & 20.0 \\
\hline \multicolumn{5}{|l|}{ Marital status } \\
\hline Single & & & 3 & 6.0 \\
\hline Married & & & 37 & 74.0 \\
\hline Divorced or widow & & & 10 & 20.0 \\
\hline \multicolumn{5}{|l|}{ Living situation } \\
\hline Live alone & & & 5 & 10.0 \\
\hline $\begin{array}{l}\text { Living with partner or } \\
\text { children }\end{array}$ & & & 18 & 36.0 \\
\hline $\begin{array}{l}\text { Living with partner and } \\
\text { children }\end{array}$ & & & 24 & 48.0 \\
\hline $\begin{array}{l}\text { Living with relatives or } \\
\text { friends }\end{array}$ & & & 3 & 6.0 \\
\hline \multicolumn{5}{|l|}{ Clinical characteristics } \\
\hline \multicolumn{5}{|l|}{ Diagnosis } \\
\hline Emphysema & & & 5 & 10.0 \\
\hline Chronic bronchitis & & & 16 & 32.0 \\
\hline COPD & & & 26 & 52.0 \\
\hline Others & & & 3 & 6.0 \\
\hline \multicolumn{5}{|l|}{ COPD classification } \\
\hline Stage II & & & 21 & 42.0 \\
\hline Stage III & & & 21 & 42.0 \\
\hline Stage IV & & & 8 & 16.0 \\
\hline $\begin{array}{l}\text { Number of years of being } \\
\text { diagnosed }\end{array}$ & 8.39 & 8.62 & & \\
\hline $\begin{array}{l}\text { Long-term treatment for } \\
\text { respiratory condition }\end{array}$ & & & 40 & 80.0 \\
\hline \multicolumn{5}{|l|}{ Pulmonary function } \\
\hline Post-BD FEV, & 1.10 & 0.51 & & \\
\hline $\begin{array}{l}\text { Post-BD FEV } \% \\
\text { predicted }\end{array}$ & 47.9 & 16.5 & & \\
\hline $\begin{array}{l}\text { Number of concomitant } \\
\text { diagnosis }\end{array}$ & 1.18 & 0.98 & & \\
\hline
\end{tabular}

Abbreviations: $\mathrm{BD}$, bronchodilator; $\mathrm{FEV}_{1}$, forced expiratory volume in I second; $\mathrm{SD}$, standard deviation.

\section{Self-efficacy}

In total, 48 and 41 questionnaires were completed in pre-test and post-test phases, respectively. Table 2 shows the mean and $Z$ scores of the CSES by groups. For the mean recorded scores of all dimensions, "physical exertion" is the only subscale that gave an overall score below the mid-point of 3.0 (mean 2.64, SD 0.66) and "intense emotional arousal" had the highest score (mean 3.30, SD 0.61). In Mann-Whitney $U$-test, no significant difference is indicated in all subscales and total score of CSES between the experimental group and control group at both baseline and post-test follow-up assessments. However, Wilcoxon signed-rank tests indicate a significant increase from baseline to post-test follow-up assessment in the total scale $(Z=-2.44, P=0.015)$ and three subscales: "intense emotional arousal" $(Z=-2.54, P=0.01)$, "physical exertion" $(Z=-2.57, P=0.01)$ and "response to weather/environment" ( $Z=-2.63, P<0.001)$ in the experimental group (Table 3).

\section{Qualitative phase}

Eighteen participants were initially invited to attend three arranged focus groups. Ten patients and one family member consented to participate in this phase of the study (Table 4). All focus groups lasted between 60 and 85 minutes. Three themes emerged during the focus group analysis that expressed their perceived self-efficacy in managing COPD after the program: 1) greater disease control, 2) improved psychosocial wellbeing and 3) perceived incapability and individuality.

The quotes were translated from Chinese (Cantonese dialect) to English by an experienced scientific writer who is fluent in both Cantonese and English, therefore, the English quotes shown in the paper are not the exact words of the participants. $\mathrm{SL}$ in the quotes refers to the moderator of the focus group.

\section{Greater disease control}

In general, participants regularly stated that they felt they had better control of their disease symptoms. They cited a number of situations where they used self-management skills, eg, adopting more controlled breathing techniques when climbing upstairs, repositioning when encountering shortness of breath and making appropriate adaptations when having sex with their partner.

Lavin: The worse condition I've faced is one I went to Gongbei ... went to Gongbei, it's like went out and bought something myself, then I became short of breath, but during the short of breath I thought ... lean there, lean there then 
Table 2 The scores of total CSES and its subgroups and baseline comparison of experimental and control groups

\begin{tabular}{|c|c|c|c|c|c|}
\hline \multirow[t]{3}{*}{ Subscales } & \multicolumn{3}{|l|}{ Baseline } & \multirow[t]{3}{*}{$\mathbf{Z}$} & \multirow[t]{3}{*}{$P$-value } \\
\hline & \multirow{2}{*}{$\frac{\text { All samples }(n=48)}{\text { Mean (SD) }}$} & \multicolumn{2}{|l|}{ Median (range ${ }^{\#}$ ) } & & \\
\hline & & SMG (n=25) & CG $(n=23)$ & & \\
\hline Negative affect & $3.23(0.63)$ & $3.10(2.90-3.60)$ & $3.40(2.60-3.90)$ & -0.73 & 0.47 \\
\hline Intense emotional arousal & $3.30(0.6 I)$ & $3.10(2.95-3.65)$ & $3.40(3.00-4.00)$ & -1.04 & 0.30 \\
\hline Physical exertion & $2.64(0.66)$ & $2.80(2.20-3.00)$ & $2.60(2.20-3.00)$ & -0.35 & 0.72 \\
\hline Response to weather/environment & $3.17(2.51)$ & $2.80(2.20-3.10)$ & $3.00(2.30-3.50)$ & -1.13 & 0.26 \\
\hline Behavioral risk factors & $3.25(0.76)$ & $3.00(3.00-3.50)$ & $3.00(2.50-4.00)$ & -0.72 & 0.47 \\
\hline Total CSES score & $3.14(0.79)$ & $3.00(2.70-3.35)$ & $3.30(2.60-3.60)$ & -0.86 & 0.39 \\
\hline
\end{tabular}

Notes: SMG refers to self-management group (experimental group); CG refers to control group; higher score means higher self-efficacy; \#Interquartile range.

Abbreviations: CSES, COPD Self-efficacy Scale; SD, standard deviation.

didn't squat down, didn't lean forward, lean on the back and breathed (demonstrates controlled breathing), then after a break, I use that thing and took a spray, not too long after the spray ... then it became ok, then not so ... not so suffered. [Focus group 2]

An action plan is included in the SMEP to help instruct the patients to avoid and manage COPD exacerbations by adjusting the dosage of the inhalers as prescribed by the physicians.

SL: Would like to ask if you have tried following this method, action plan?

Karen: I have never been in such an emergency situation.

Lavin: I tried twice ...

SL: You tried twice ...

Lavin: I tried twice.

SL: Followed the method?

Lavin: Followed the method ... followed that method twice.

Chris: [interrupts] Are you regularly trying?

Lavin: ... I ... I am not trying this regularly.

SL: During exacerbation?

Chris: I did that when I was [having sex]. [Focus group 2]

\section{Improved psychosocial well-being}

The patients presented with a more positive approach and life belief following the SMEP, which equipped them to live with their chronic condition with confidence.

Nick: It means I understand what kind of disease we are having through the workshop, the main problems of it, so, we learnt all these through the workshop, although it is dreadful, still if you pay enough attention to all these, the lifespan is still able to be extended, can be treated well in time. [Focus group 1]
Chris: Then the workshop, learnt a lot ... it was really effective! I still have few years left for my life, I still can finish something which I really want to do. [Focus group 2]

These two participants had previously experienced episodes of respiratory failure, associated with the severe level (Stage IV) of their COPD, prior to participation in this study. They expressed that self-management can help to prolong their life span, and they anticipated for living the rest of life with more meaning. These two themes highlight perceived positive benefits of SMEP for COPD patients. In addition, a third theme emerged from the data that outlined potentially negative consequences of SMEP in this patient group.

\section{Perceived incapability and individuality}

It was also noticeable that participants often attributed poor self-management mastery to personal incapability. The group highlighted poor memory as the main obstacle to practising efficient disease management.

Lavin: Completely memorized ... completely memorized, couldn't memorize all of them! Eg, that (the gesture for the breathing exercise) that couldn't completely memorize

Karen: [interrupts] O, I have totally forgotten as well.

Lavin: ... I really couldn't memorize! That book

Karen: [interrupts] Those styles, couldn't memorize those styles.

Lavin: ... those like that what so called "The Dragon Sways its Tail" really don't know

Karen: [interrupts] Totally forgot.

Lavin: ... totally forgotten, really have this problem, confused me. [Focus group 2]

However, the participants also believed that the impact of self-management varied from person to person, which is associated with individual's concept or philosophy of health maintenance. Some participants repeatedly highlighted this individual difference in the focus groups, one of them said: 


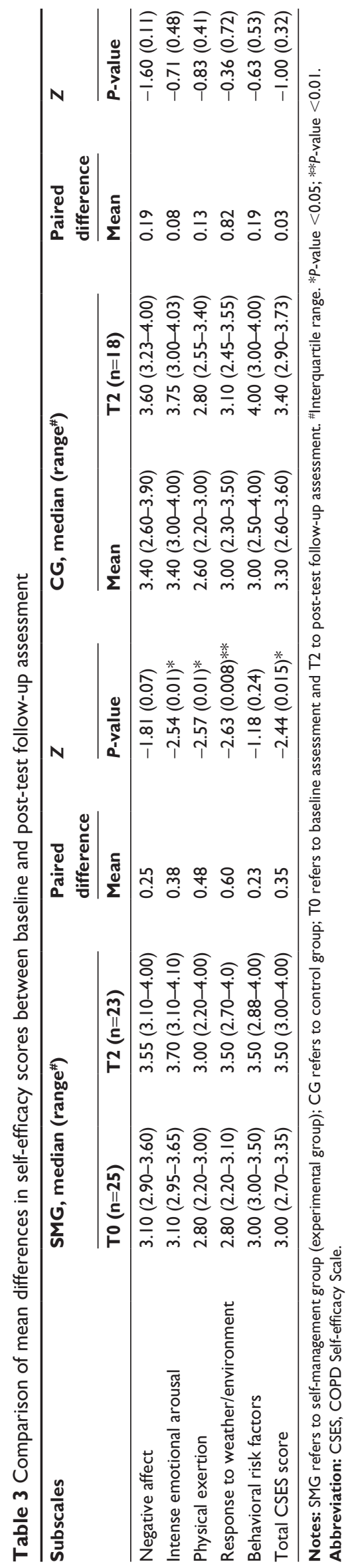

Table 4 Pseudonyms and demographic characteristics of participants in focus groups

\begin{tabular}{lllll}
\hline $\begin{array}{l}\text { Focus } \\
\text { groups }\end{array}$ & Name & Age/sex & $\begin{array}{l}\text { COPD } \\
\text { staging }\end{array}$ & $\begin{array}{l}\text { Education } \\
\text { level }\end{array}$ \\
\hline I & Nick & 6 I/M & IV & Secondary \\
& Amy & $57 / \mathrm{F}$ & II & Primary \\
& Wilson & $73 / \mathrm{M}$ & II & Primary \\
& Ivan & $73 / \mathrm{M}$ & III & Primary \\
2 & Lavin & $63 / \mathrm{M}$ & III & Primary \\
& Leon & $64 / \mathrm{M}$ & III & Primary \\
& Chris & $6 \mathrm{I} / \mathrm{M}$ & III & Primary \\
& Karen & $65 / \mathrm{F}$ & III & Primary \\
3 & Winnie & $47 / \mathrm{F}$ & II & Primary \\
& Mr Lee & $63 / \mathrm{M}$ & IV & Secondary \\
& Mrs Lee* & $62 / \mathrm{M}$ & III & Primary \\
\hline
\end{tabular}

Note: *Mrs Lee is the wife of Mr Lee.

Abbreviations: $M$, male; $F$, female.

Karen: My stomach can't tolerate food in cold nature, it means the food like melons, some people said, papaya is good for some disease like having constipation, I can't take those. Also like banana, both food are not suitable to me, my body is like this. [Focus group 2]

\section{Discussion}

Within COPD, SMEPs are very varied in components and delivered in various ways. ${ }^{25}$ The SMEP established in this study comprised most of the components of self-management interventions, except relaxation. To our knowledge, this is the first study to examine the effects of SMEP in improving the self-efficacy of COPD patients in Macau. We have successfully illustrated that the integration of SMEP into conventional COPD therapy can maximize the management of illness of patients and enhance performance of their daily living activities. Such findings are in line with the previous reports describing the central and explanatory roles of selfefficacy in the analysis and prediction of individual behavioral changes. ${ }^{38,40,41}$ After receiving the SMEP, our patients in the experimental group showed greater improvement in general self-efficacy and three specific dimensions of self-efficacy (ie, intense emotional arousal, physical exertion and weather/environment). Several COPD studies also demonstrated positive outcomes; this is consistent with our findings. One RCT study reported significant improvement in total and all subscale scores of CSES in the experimental group. ${ }^{42}$ Other studies demonstrated improvement of selfefficacy in self-management behaviors in COPD patients for up to 2 years after self-management education. ${ }^{15,43}$ Wong et $\mathrm{al}^{38}$ and Davis et $\mathrm{al}^{44}$ indicated that only functional aspects (ie, walking and physical exertion) can be improved by self-management intervention. Intriguingly, contradictory observations have been reported in other COPD studies. ${ }^{45,46}$ 
These discrepancies may be attributed to the lack of standardization for the content or structure of self-management education and different measurements used for self-efficacy assessment. ${ }^{47}$ It is also noteworthy to mention that the evaluation of self-management interventions for COPD patients in China has predominantly focused on biomedical parameters and health-related quality of life. ${ }^{48,49}$ but rarely on cognitive behavioral performance. Therefore, this study suggested the mediating role of self-efficacy in self-management intervention for COPD patients of Chinese ethnicity.

In the following paragraphs, the quantitative and qualitative findings were connected to answer the explanatory research question. First, participants in the experimental group showed improvement in the total score of CSES. This effect is illustrated in this quote from one participant:

Chris: Before, my condition ... was very serious, through the check up by doctor, it was certified ... ha ... by the hospital, the indicator of my lung function was only 31 , normal people is 80 , so I thought it's hopeless when I knew the fact! Waited for my death at home, just a matter of time! Then afterwards learnt from the program ... learnt a lot, improved, in terms of improvement, in particular the dietary, ... like I ate more side dish, vegetable, it is documented in the handbook, like reducing the portion of carbohydrate, the intake of carbohydrate would be resulted in the production of carbon dioxide of the body, I know I should be very careful as mentioned here. Sometimes I took vegetable as rice. [Focus group 2]

This quote illustrates that the patient gained confidence in their diet management (efficacy expectation) and stated the improvement he believed (outcome expectation) by highlighting the contrast in the level of confidence he had before and after receiving SMEP. The outcome and efficacy expectations led the participants to perceive better self-appraisal of efficacy when adopting self-management skills. ${ }^{50}$

In addition, three dimensions of self-efficacy, namely, physical exertion, response to weather/environment and intense emotional arousal also improved in the experimental group after delivery of the SMEP. The first theme "greater disease control" emerged from the qualitative findings and shows consistency with the quantitative results of improvement in self-efficacy during physical exertion. Functional capability should be essential to perform social activities and prominent in an individual's daily life as gaining confidence in engaging in social activities was identified to enable COPD patients to overcome feelings of social isolation. ${ }^{51}$ A study of Chinese COPD patients also indicated that social coping strategies could help an individual reduce their psychological distress and increase their psychological well-being. ${ }^{52}$ Therefore, functional improvement would appear to be a key factor for COPD patients.

Weather or environmental factors have also been identified as risk factors in COPD. ${ }^{53}$ Quantitative findings in this study demonstrated that participants had greater confidence to avoid and deal with the adverse effects of weather changes and environmental triggers following their SMEP intervention. One focus group participant stated:

Chris: For me I mainly followed the instruction for breath-

ing, and also to avoid ... like those tobacco, temples, car

park or those related to exhaust, tried hard to avoid all these

factors. [Focus group 2]

From the quantitative findings, participants demonstrated higher levels of confidence managing difficulty in breathing during adverse emotions, eg, fear, anger and anxiety after receiving SMEP. However, this point did not really emerge from the qualitative phase. The participants in the focus groups appeared reluctant to admit emotional problems.

Mr Lee: I don't have those emotions, I'm not anxious.

Winnie: [interrupts] (hehehe) Mr Lee is similar with

me, I'm not anxious too.

Mr Lee: ... I don't even have pressure, I'm always relaxed (laugh gently).

Winnie: [interrupts] I only have problem when I climb up staircases.

Participants did not make direct attribution to the SMEP in relation to equipping them with confidence to encounter and deal with adverse emotions. They mainly expressed that periods of intense emotion did not bother them in disease management. From this perspective, an improvement in selfefficacy derived from participating in the SMEP may have led the participants to enhanced level of psychosocial well-being, as they thought adverse emotion would not affect them. Alternatively, the improvement of self-efficacy in managing intense emotion in the participants might not merely be the effects of SMEP, as personal control over intense emotions may also be influential. The ethnographic characteristic of the Chinese tends to make them less likely to express their real feelings and lead them to excessive rumination over emotional expression..$^{54}$ Therefore, the participants tended to place less emphasis on the effects of personal emotion to their own health.

In addition, the theme "perceived incapability and individuality" emerged in the focus groups highlighting 
the potential influence of one's perceptual constancy in the development of their efficacy expectation. In the study by Leung et al, ${ }^{35}$ the Chinese with COPD were found to have a relatively poor psychosocial adjustment as a perception of decreased energy level may have prevented the patients from adopting a more adaptive approach to coping with their condition. Poor memory, as emphasized by study participants, could be related to decreased implementation of self-management techniques. This may also lead to feelings of inferiority that may make the patients give up easily and worry about performing the techniques poorly. ${ }^{54} \mathrm{With}$ regard to perceived individuality, a patient in this study adopted the Yin-Yang theory of traditional Chinese medicine in relation to diet, accordingly cold and heat properties of food can help to regulate the pathophysiological condition of the body. ${ }^{55}$ She believed that individual difference would induce varied effect even with the same diet. This implies that the adoption of self-management might vary from person to person under this cultural influence.

\section{Conclusion}

The results and findings presented in this mixed study connect the quantitative and qualitative perspectives, which indicate the positive role of SMEP may have in COPD. Our program clearly improved the self-efficacy of COPD patients in the Chinese population of Macao. It also provided them with the feeling of able to better control their disease and improve psychosocial well-being. Of note, our qualitative data demonstrated that individual perceptual constancy of patients could also be the determining factors modulating the effectiveness of SMEP. Therefore, investigation of the effects of such factors in SMEP for COPD patient in Macau will be useful to enable further adjustment and refinement of this interventional program.

Possible weaknesses of our study are mainly related to the potential bias underlying the research design and to the sampling structure. Although block randomization and blinding were adopted in the research design, the influence of participant preference may still be a potential confounder of true randomization (MRC 2000). This could happen when the participants had a treatment preference, then they were likely to expect and achieve more positive outcomes. However, it is very difficult to avoid this type of bias in interventional study. The relatively small sample size could also be seen as a limitation in this study. Exhaustive efforts were applied to made up for the sample size through employing a sequential qualitative data collection and recruiting additional participants from the community care centers. In addition, the health beliefs of the Chinese population should be considered, which, however, have not been further discussed because it is not possible to explore this area in more detail within the scope of this study. Despite these efforts, being an exploratory phase of RCT, this study employed rigorous procedures to develop and evaluate a complex intervention, as outlined by MRC. The use of mixed-methods sequential explanatory design ensured that we captured a greater insight into the personal experience of the intervention by the participants.

Under the guidance of MRC framework for evaluation of complex intervention, an exploratory trial could not provide evidence to the same level of rigor as an RCT does. Despite this limitation, this study does serve a different purpose as the results interlinked the concepts of self-management, self-efficacy and mixed methods, as such it provided a foundation for the development of a full large-scale RCT. Therefore, the implementation of SMEP as an initiative step to the continual intervention process for the COPD patients in Macau is recommended. Follow-up study in examining the attributing effect of each component of the SMEP to the self-management performance of COPD patients is needed. Further exploration of the long-term effect, ie, 9-12 months of SMEP, is also warranted. Taken together, the mixed quantitative and qualitative approach not only suggested that the Chinese population of COPD patients in Macau can be benefited from SMEP, but it also enhanced the overall design of an experiment. With the increasing burden of noncommunicable chronic illness in the world, this study also provided insight for SMEP health care delivery to other forms of chronic illnesses in Chinese populations. It is important that these cultural considerations are taken into account when developing this form of intervention. This form of mixedmethods approach is recommended in future SMEP COPD studies, giving a very rigorous and comprehensive perspective of this complex chronic respiratory condition.

\section{Acknowledgments}

Dr Cheng Kuan, Ms Iris Lou and Leong Sok Man are acknowledged for their effort and advice. Special thanks are given to Dr Susanne Kean, Sarah Lau and Joanne Tam for their assistance in qualitative data collection and analysis. This study was funded by Fundo para o Desenvolvimento das Ciências e da Tecnologia of Macau (Project code: 007/2011/A). This research was presented at the 25th International Nursing Research Congress held at Hong Kong, July 24-28, 2014, as a presentation with interim findings. The abstract and presentation are stored online at Virginia 
Henderson International Nursing e-Repository by STTI International Nursing Research Congress.

\section{Author contributions}

Both authors contributed to the design of the study and to the drafting and revision of the paper. Both authors approved the final manuscript and agreed to be accountable for all aspects of the work.

\section{Disclosure}

The authors report no conflicts of interest in this work.

\section{References}

1. Aït-Khaled N, Enarson D, Bousquet J. Chronic respiratory diseases in developing countries: the burden and strategies for prevention and management. Bull World Health Organ. 2001;79(10):971.

2. WHO. World Health Statistics 2008. Available from: http:// www.who.int/whosis/whostat/EN_WHS08_Full.pdf. Accessed November 19, 2009.

3. Lopez AD, Shibuya K, Rao C, et al. Chronic obstructive pulmonary disease: current burden and future projections. Eur Respir J. 2006;27(2): $397-412$.

4. National Institute for Health and Care Excellence. Chronic obstructive pulmonary disease in adults; 2011 [updated February 2016]. Available from: https://www.nice.org.uk/guidance/qs10/resources/chronicobstructive-pulmonary-disease-in-adults-2098478592709. Accessed April 12, 2017.

5. Global Initiative for Chronic Obstructive Pulmonary Disease. GOLD 2017 Global Strategy for the Diagnosis, Management and Prevention of COPD. Available from: http://goldcopd.org/gold-2017global-strategy-diagnosis-management-prevention-copd/. Accessed April 12, 2017.

6. Lemmens KM, Nieboer AP, Huijsman R. A systematic review of integrated use of disease-management interventions in asthma and COPD. Respir Med. 2009;103(5):670-691.

7. Effing T, Monninkhof EM, van der Valk PD, et al. Self-management education for patients with chronic obstructive pulmonary disease. Cochrane Database Syst Rev. 2007;4:CD002990.

8. DSEC; Government of Macao Special Administrative Region; Statistics and Census Service. Boletim Estatistico; Óbitos segundo as primeiras causas antecedentes de morte (2004-2006) [Annual Statistics; Deaths according to the primary causes of death]; 2009. Available from: http://www.ssm.gov.mo/statistic/2009/data/link/pdf/1-9.pdf. Accessed February 23, 2013. Portuguese.

9. DSEC; Government of Macao Special Administrative Region; Statistics and Census Service. Boletim Estatistico; Óbitos segundo as primeiras dez causas antecedentes de morte [Annual Statistics; Deaths according to the ten primary causes of death]; 2009. Available from: http:// www.ssm.gov.mo/statistic/2011/data/pdf/1-9.pdf. Accessed February 23, 2013. Portuguese.

10. DSEC; Government of Macao Special Administrative Region; Statistics and Census Service. Survey on Manpower Needs and Wages - Gaming Industry; 2014. Available from: http://www.dsec.gov.mo/Statistic. aspx?NodeGuid=6289ca07-25cc-450b-8499-4e34765c1769. Accessed October 15, 2014.

11. Wu S. [An Investigation of Health Condition of Workers (Dealers) in Macau Casinos]; 2010. Available from: http://www.kwnc.edu.mo/web/ Research/research_001.pdf. Accessed October 10, 2014. Chinese.

12. Horne R, Weinman J. Self-regulation and self-management in asthma: exploring the role of illness perceptions and treatment beliefs in explaining non-adherence to preventer medication. Psychol Health. 2002;17(1): $17-32$.
13. Kohler CL, Fish L, Greene PG. The relationship of perceived selfefficacy to quality of life in chronic obstructive pulmonary disease. Health Psychol. 2002;21(6):610-614.

14. Lau-Walker M. Predicting self-efficacy using illness perception components: a patient survey. Br J Health Psychol. 2006;11:643-661.

15. Lorig KR, Ritter P, Stewart AL, et al. Chronic disease self-management program - 2-year health status and health care utilization outcomes. Med Care. 2001;39(11):1217-1223.

16. Tian Y, Zhang J, Miao HC. Effect evaluation of health literacy interventions for resident in Yangchong city. Jiangsu J Prev Med. 2011; 22(6):13-14.

17. Yin Z, Geng G, Lan X, et al. Status and determinants of health behaviour knowledge among the elderly in China: a community-based crosssectional study. BMC Public Health. 2013;13:710-720.

18. Li XW. Cognition of residents in Taiyuan area on self-medication and their self-medication behaviour. China Pharm. 2008;19(19): 1518-1520.

19. Tian M, Chen Y, Zhao R, et al. Chronic disease knowledge and its determinants among chronically ill adults in rural areas of Shanxi Province in China: a cross-sectional study. BMC Public Health. 2011;11:948.

20. Kaplan RM, Atkins CJ, Reinsch S. Specific efficacy expectations mediate exercise compliance in patients with COPD. Health Psychol. 1984;3(3):223-242.

21. Kaptein AA, Scharloo M, Fischer MJ, et al. 50 years of psychological research on patients with COPD - road to ruin or highway to heaven? Respir Med. 2009;103(1):3-11.

22. Simpson E, Jones M. An exploration of self-efficacy and self-management in COPD patients. Br J Nurs. 2013;22(19):1105-1109.

23. Dritsaki M, Johnson-Warrington V, Mitchell K, Singh S, Rees K. An economic evaluation of a self-management programme of activity, coping and education for patients with chronic obstructive pulmonary disease. Chron Respir Dis. 2016;13(1):48-56.

24. Zwerink M, Kerstjens HA, van der Palen J, et al. (Cost-) effectiveness of self-treatment of exacerbations in patients with COPD: 2 years follow-up of a RCT. Respirology. 2016;21(3):497-503.

25. Jolly K, Majothi S, Sitch AJ, et al. Self-management of health care behaviours for COPD: a systematic review and meta-analysis. Int $J$ Chron Obstruct Pulmon Dis. 2016;11:305-326.

26. Ministry of Health, Macau. Health Science Journal of Macao; reference to all journal papers published between 2002-2010. Available from: http://www.ssm.gov.mo/portal/. Accessed March 5, 2013. Chinese.

27. KWNC. Macau Journal of Nursing; reference to all journal papers published between 2002-2011. Available from: http://www2.kwnc. edu.mo/?page_id=6038. Accessed March 5, 2013. Chinese.

28. DSEC; Government of Macao Special Administrative Region; Statistics and Census Service. Results of 2011 population census; 2012. Available from: http://www.dsec.gov.mo/Statistic.aspx?lang=enUS\&NodeGuid=8d4d5779-c0d3-42f0-ae71-8b747bdc8d88. Accessed February 23, 2013.

29. MRC. Developing and Evaluating Complex Intervention - New Guidelines; 2008. Available from: www.mrc.ac.uk/complexinterventions guidance. Accessed June 19, 2010.

30. Creswell JW, Plano Clark VL. Designing and Conducting Mixed Methods Research. 2nd ed. Los Angeles, London: SAGE; 2011.

31. Blackwood B. Methodological issues in evaluating complex healthcare interventions. J Adv Nurs. 2006;54(5):612-622.

32. GOLD. Global Strategy for the Diagnosis, Management, and Prevention of Chronic Obstructive Pulmonary Disease; 2008 [updated 2008]. Available from: www.goldcopd.org. Accessed October 22, 2009.

33. Barbour R, editor. Introducing Qualitative Research - A Student Guide to the Craft of Doing Qualitative Research. London: SAGE Publications Ltd.; 2008.

34. Guthrie SJ, Hill KM, Muers MF. Living with severe COPD. A qualitative exploration of the experience of patients in Leeds. Respir Med. 2001;95(3):196-204.

35. Leung YM, Alexander M, Chun CJP. Coping and adjustment in Chinese patients with chronic obstructive pulmonary disease. Int J Nurs Stud. 2002;39(4):383-395. 
36. Punekar YS, Rodriguez-Roisin R, Sculpher M, Jones P, Spencer M. Implications of chronic obstructive pulmonary disease (COPD) on patients' health status: a western view. Respir Med. 2007;101(3):661-669.

37. Walters JA, Turnock AC, Walters EH, Wood-Baker R. Action plans with limited patient education only for exacerbations of chronic obstructive pulmonary disease. Cochrane Database Syst Rev. 2010;5: CD005074.

38. Wong KW, Wong FKY, Chan MF. Effects of nurse-initiated telephone follow-up on self-efficacy among patients with chronic obstructive pulmonary disease (vol 49, p 210, 2005). J Adv Nurs. 2005;49(5): 561-561.

39. Wigal JK, Creer TL, Kotses H. The COPD self-efficacy scale. Chest. 1991;99(5):1193-1196.

40. Bandura A. Health promotion by social cognitive means. Health Educ Behav. 2004;31(2):143-164.

41. Warwick M, Gallagher R, Chenoweth L, Stein-Parbury J. Selfmanagement and symptom monitoring among older adults with chronic obstructive pulmonary disease. J Adv Nurs. 2010;66(4):784-793.

42. Kara M, Aşti T. Effect of education on self-efficacy of Turkish patients with chronic obstructive pulmonary disease. Patient Educ Couns. 2004;55(1):114-120.

43. Siu AM, Chan CC, Poon PK, Chui DY, Chan SC. Evaluation of the chronic disease self-management program in a Chinese population. Patient Educ Couns. 2007;65(1):42-50.

44. Davis AH, Carrieri-Kohlman V, Janson SL, Gold WM, Stulbarg MS Effects of treatment on two types of self-efficacy in people with chronic obstructive pulmonary disease. J Pain Symptom Manage. 2006;32(1): 60-70.

45. Bucknall CE, Miller G, Lloyd SM, et al. Glasgow supported selfmanagement trial (GSuST) for patients with moderate to severe COPD: randomised controlled trial. BMJ. 2012;344:e1060.
46. Lemmens KM, Nieboer AP, Rutten-Van Mölken MP, et al. Application of a theoretical model to evaluate COPD disease management. BMC Health Serv Res. 2010;10:81.

47. Stellefson M, Tennant B, Chaney JD. A critical review of effects of COPD self-management education on self-efficacy. ISRN Public Health. 2012:1-10 (Article ID 152047).

48. Yu SH, Guo AM, Zhang XJ. Effects of self-management education on quality of life of patients with chronic obstructive pulmonary disease. Int J Nurs Stud. 2014;1(1):53-57.

49. Zhou Y, Hu G, Wang D, et al. Community based integrated intervention for prevention and management of chronic obstructive pulmonary disease (COPD) in Guangdong, China: cluster randomised controlled trial. BMJ. 2010;341:c6387.

50. Bandura A. Social Foundations of Thought and Action: A Social Cognitive Theory. Englewood Cliffs, NJ: Prentice-Hall; 1986.

51. Williams V, Bruton A, Ellis-Hill C, McPherson K. The effect of pulmonary rehabilitation on perceptions of breathlessness and activity in COPD patients: a qualitative study. Prim Care Respir J. 2009;18(1): 45-51.

52. Hsu W-Y, Chen M-C, Wang T-H, Sun S-H. Coping strategies in Chinese social context. Asian J Soc Psychol. 2008;11:150-162.

53. GOLD. Global Strategy for the Diagnosis, Management, and Prevention of Chronic Obstructive Pulmonary Disease. Global Initiative for Chronic Obstructive Lung Disease, Inc.; 2013.

54. Chen SXH, Cheung FM, Bond MH, Leung JP. Decomposing the construct of ambivalence over emotional expression in a Chinese cultural context. Eur J Personal. 2005;19(3):185-204.

55. Yin YT, Li XW, Dong Y, Shi JR. [Research progress in biological basis of cold and heat essence of Chinese medicine]. J Chin Integr Med. 2012;10(12):1328-1335.
International Journal of COPD

\section{Publish your work in this journal}

The International Journal of COPD is an international, peer-reviewed journal of therapeutics and pharmacology focusing on concise rapid reporting of clinical studies and reviews in COPD. Special focus is given to the pathophysiological processes underlying the disease, intervention programs, patient focused education, and self management protocols.

\section{Dovepress}

This journal is indexed on PubMed Central, MedLine and CAS. The manuscript management system is completely online and includes a very quick and fair peer-review system, which is all easy to use. Visit http://www.dovepress.com/testimonials.php to read real quotes from published authors. 